\title{
软 X射线检测隐蔽病虫的探讨
}

\author{
原 德 法 \\ （上海市农业科学院作物育种我培研究所）
}

软系 X 射线不仅适用于轻花金属及非金属探伤,软组织肿瘤诊断等方面,也可以作为检测 植物体内，特别是种子内部隐蔽病虫害的手段。瑞典学者 Gustafsson 等 ${ }^{[2]}$ 早在 1956 年就用 于观察林木种子空粒与虫害, 其后印度 Swaminathan 等 $(1961)^{[2]}$. 日本土井弥太郎(1963) ${ }^{[3]}$. 分别用于小麦、玉米种子内部潜伏虫害及稻茎内蛽虫的观察. 我国徐国洤 ${ }^{[4]}$. 等 1963 年也 曾在这方面做了研究. 为了扩大软 X 射线在植物保护方面的应用,作者于 1980-1982 年利用 国产 DGX-4 型, Hy-35 型两种仪器, 通过透视摄影和荧光直观, 就一些隐蔽病虫的发育和为 害程度做了多方面的观察。

\section{一、检测范围}

利用软 X 射线摄影(苂光)能观察的隐蔽虫害及病害有以下几类:

（1）种子内虫害: 作者应用软 X 射线摄影法观察谷蛾、米象、蚕豆象、踠豆象等等,多种潜 伏在种子内部的害虫, 在检测害虫的虫口密度、危害率, 以及虫体发育阶段等方面, 与解剖所得 结果相吻合. 图 1 为谷蛾 (Tinea granella L.) 幼虫、蛹在稻谷中潜伏及危害状况;图 2 为米象 (Sitophilus Oryae L,) 卵、幼虫在小麦籽粒中潜伏, 发育及危害状况; 图 3 为䖽豆象 (Bruchusru fimanus Boheman）内虫在䖽豆籽粒中发育状况.

（2）茎内害虫: 蛙食茎干或果实的害虫，一般不易察觉. 应用软 X射线摄影不仅能在不 破坏被害植株和害虫的自然状态下进行观察。而且可以观察到害虫的密度、妵食的潜伏位置， 图 4 为淢萢透翅蛾 (Paranthrene regalis Butler) 在葡萄枝条中的幼虫及其被害隧洞. 图 5 为大 蛽 (Sesamia inferns Walker) 在水稻茎干内的生育状态.

（3）革内虫态: 包括多种树木农作物革习性的害虫,均可用软 X射线法进行观测, 并能根 据虫体大小、形状、皮层皱缩程度, 鉴别其生死与虫态变化. 图 7 为果树大黄娥 (Cryptothelea formosicola Strand）革内的幼虫.

（4）植物体内菌核: 作物残杆中真菌病原菌核的有无和多察，是判断该地区菌原污染程 度的一个重要指标. 用软 $\mathrm{X}$ 射线摄影检查十字花科,禾本科植物残杆中菌核病的菌核密度、分 布位置和形态类型也是十分准确有效的. 图 6 系油菜菌核病菌(Sclerotinia Sclerotiorum (Lib.) Debary)的菌核在油菜残杆中的分布状况。

\section{二、仪器与使用技术}

我们选用国产 DGX-4 型和 $\mathrm{Hy}-35$ 型软 $\mathrm{X}$ 射线仪,均采用钼 (Mo) 靶、铍窗软 X 射线发

本文 1982 年 5 月 17 日收到. 
射管, 特微波长 $0.63-0.71 \AA$. 在摄影观察上述害虫和菌核时, 图象清晰, 分就力也很高. 无 其是 $\mathrm{Hy}-35$ 型, 还采用箱式组装, 全防护, 附有荧光观察装置, 在室内适于被害种子等样本箱 体内撒影或荧光直观，操作安全; 在室外观察时, 可御下机头、控制器, 置于田间或果树中就地 摄影.

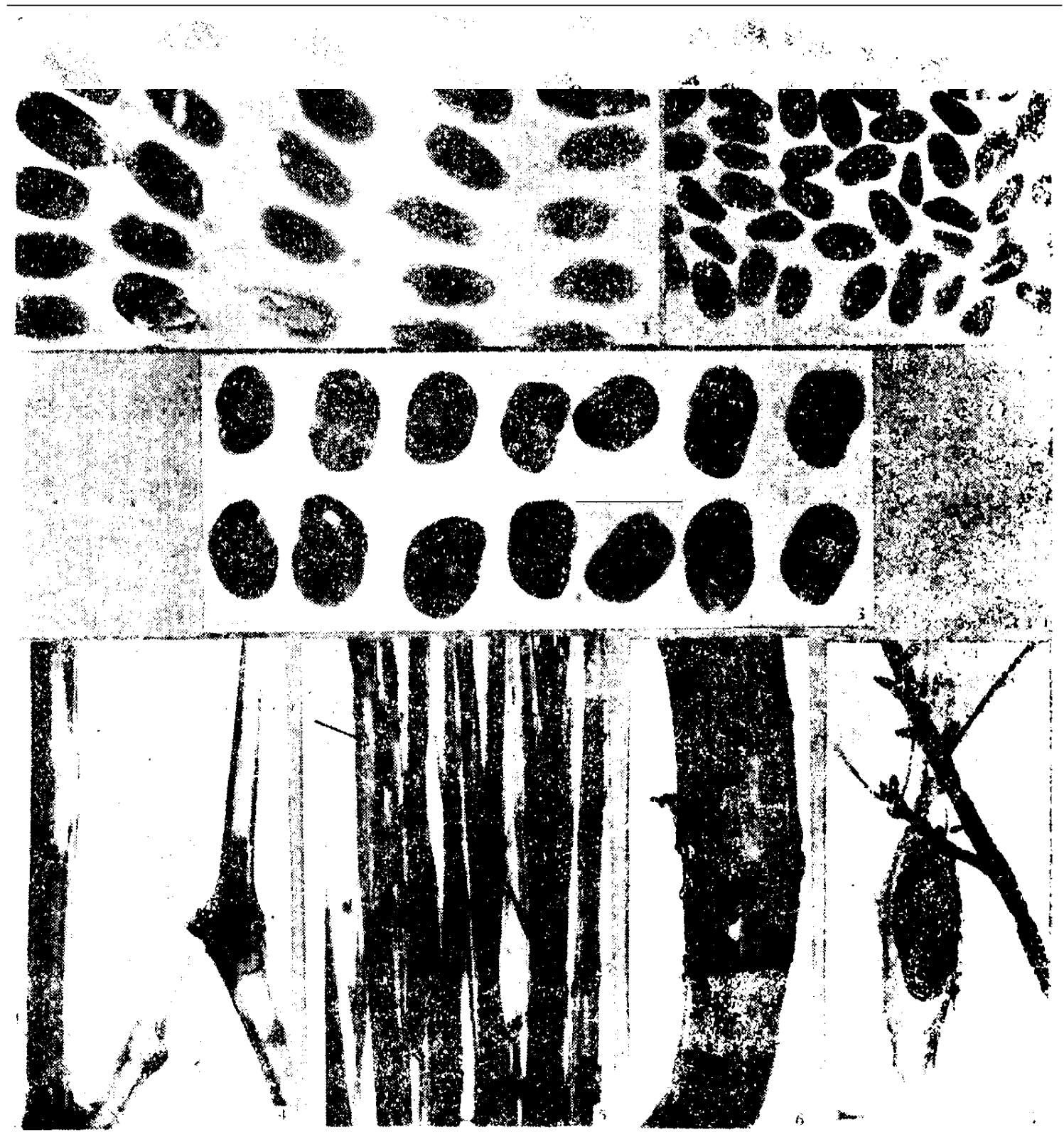

图 1-7

1. 谷蛾幼虫、蛹在稆谷内潜伏及其危害状况; 2. 米象幼虫在小麦抺柆中发有及危害状况;

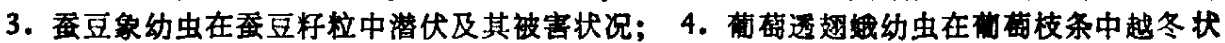

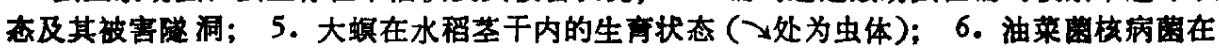

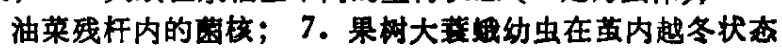

软 X射线仪的摄影条件，胶片感光强度决定于所用发射电压、电流、曝光时间，以及被摄物 的厚度、紧密度,焦片距有关. 由于样本不规则, 很难用公式计算. 一般被摄物厚而紧密,焦片 距 (发射焦点到感光片的距离) 又较远的,需要放射剂量也就越高. 附部分样本实际摄影条件 如下: 


\begin{tabular}{|c|c|c|c|c|c|}
\hline 检测对象 & 被害对象 & 电压 (kV) & 电流 $(\mathrm{m} A)$ & 时间 (S) & 焦片匜 $(\mathrm{cm})$ \\
\hline 大薮幼虫 & 果树 & 30 & 2.5 & 30 & 20 \\
\hline 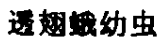 & 蔽繁枝条 & 35 & 4 & 60 & 20 \\
\hline 趧豆象幼虫 & 䖯豆种子 & 30 & 3 & 40 & 20 \\
\hline 谷蛾幼虫 & 稻 & 30 & 3 & 20 & 20 \\
\hline 米象幼虫 & 小麦种子 & 30 & 3 & 20 & 20 \\
\hline 数 & 油来牫杆 & 30 & 3 & 30 & 30 \\
\hline
\end{tabular}

*软 X仪: Hy-35, 胶片: 8DIN 黑白片,黑纸包装。

\section{三、讨论与小结}

（1）利用软 $\mathrm{X}$ 射线摄影法观宗种子(包括苗木)和兄粮的潜伏害虫, 可以代替人工剥查, 既 省工、省力,又不破坏样本. 因此可用于检疫与仓库管理,尤其适用于名贵种子的检疫.

（2）软 X 射线振影图象清晰，分辦力强，能够在不损伤作物及害虫本身的前提下,定株、定 虫地连续振影,积累资料,可以作为生态研究、预测预报、直观教学的手段.

（3）荻光直观用于诊断大型虫体样本比较方便, 也省成本, 但分辩率比摄影显著降低,观 察细小幼虫和虫卵等不宜采用。

（4） Hy-35 型软 X 射线仪具有体积小、造价低、防护性能好的特点,更便于推广.

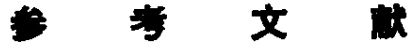

[1] Gustafsson, A. \& Simak, M., Congr. Un. Int. Rech. For. XII Congress, Oxford, 1956, 1-18.

[2] Swaminatban, M. S. \& Kamra, S. K., Indian. Journal of Genetics and Plant Breeding, 21 (1961), 2 : $129-135$.

[3]土井弥太郎，X線とソフテックス写真(小泉萰太),共立出版株式会社出版，1963，107-108.

[4]徐国洤，植物检度(浙农大汇编),上海科学技术出版社，1978，485-488. 